\title{
Vernet Syndrome by Varicella-Zoster Virus
}

\author{
Yill Ryun Jo, $\mathrm{MD}^{1}$, Chin Wook Chung, $\mathrm{MD}^{2}$, Jung Soo Lee, $\mathrm{MD}^{2}$, Hye Jeong Park, $\mathrm{MD}^{1}$ \\ ${ }^{1}$ Department of Rehabilitation Medicine, Seoul St. Mary's Hospital, The Catholic University of Korea \\ College of Medicine, Seoul; ${ }^{2}$ Department of Rehabilitation Medicine, Uijeongbu St. Mary's Hospital, \\ The Catholic University of Korea College of Medicine, Uijeongbu, Korea
}

\begin{abstract}
Vernet syndrome involves the IX, X, and XI cranial nerves and is most often attributable to malignancy, aneurysm or skull base fracture. Although there have been several reports on Vernet's syndrome caused by fracture and inflammation, cases related to varicella-zoster virus are rare and have not yet been reported in South Korea. A 32-year-old man, who complained of left ear pain, hoarse voice and swallowing difficulty for 5 days, presented at the emergency room. He showed vesicular skin lesions on the left auricle. On neurologic examination, his uvula was deviated to the right side, and weakness was detected in his left shoulder. Left vocal cord palsy was noted on laryngoscopy. Antibody levels to varicella-zoster virus were elevated in the serum. Electrodiagnostic studies showed findings compatible with left spinal accessory neuropathy. Based on these findings, he was diagnosed with Vernet syndrome, involving left cranial nerves, attributable to varicella-zoster virus.
\end{abstract}

Keywords Varicella-zoster virus, Cranial nerves

\section{INTRODUCTION}

Vernet syndrome refers to paralysis of the IX, X, and XI cranial nerves traversing the jugular foramen. A variety of lesions can involve the jugular foramen, such as tumors, vascular lesions, infections, and trauma [1].

By the early 1900s, Hunt [2] described cranial neuropathies presented with erythematous vesicular rashes on the head and neck as a result of varicella-zoster virus.

Received June 30, 2012; Accepted August 22, 2012

Corresponding author: Hye Jeong Park

Department of Rehabilitation Medicine, Seoul St. Mary's Hospital, The Catholic University of Korea College of Medicine, 222 Banpo-daero, Seocho-gu, Seoul 137-701, Korea

Tel: +82-2-2258-2282, Fax: +82-2-2258-2825, E-mail: petitehj01@naver. com

(ㄷ) This is an open-access article distributed under the terms of the Creative Commons Attribution Non-Commercial License (http://creativecommons. org/licenses/by-nc/3.0) which permits unrestricted noncommercial use, distribution, and reproduction in any medium, provided the original work is properly cited.

Copyright $\odot 2013$ by Korean Academy of Rehabilitation Medicine
Hunt [2] surmised that the gasserian, geniculate, petrous, accessory, jugular, plexiform, and second and third cervical dorsal root ganglia formed a chain by which inflammation of a single ganglion could extend to nearby ganglia.

In South Korea, two cases of Vernet syndromes have been reported as a result of skull base fracture and nonspecific focal inflammation of the neck, respectively $[3,4]$. However, no case of Vernet syndrome due to varicellazoster virus has been reported. The following outlines a case of Vernet syndrome caused by varicella-zoster virus.

\section{CASE REPORT}

A 32-year-old man with left shoulder weakness was consulted to our department for an electrodiagnostic study. This patient had been admitted to the department of otolaryngology in our hospital due to sore throat, left earache, hoarseness, and swallowing difficulty, which developed three weeks before the study. On admission, 
vesicular rashes on the patient's left ear were detected (Fig. 1). Speech audiometry, the stapedial reflex test, tympanometry, the auditory brainstem response threshold test, and the pure tone test were all normal. Laryngoscopy showed that his left vocal cord was hypomobile (Fig. 2A). On neurological examination, he showed impaired gag reflex on the left side and deviation of the uvula to the right side (Fig. 2B). There was no impairment of facial sensation and motion, no tongue deviation or nystagmus. He had no particular underlying disease. Records revealed that twenty years ago, the patient had tympanoplasty in his left ear due to injury by trauma.

Serological tests showed negative results for herpes simplex virus immunoglobulin $\mathrm{M}$, and positive results for herpes simplex virus immunoglobulin G, and varicellazoster virus immunoglobulin $\mathrm{G}$ and $\mathrm{M}$. These findings were consistent with acute varicella-zoster virus infection. Magnetic resonance imaging (MRI) of the temporal bone revealed no nodular lesions in the left jugular fora-

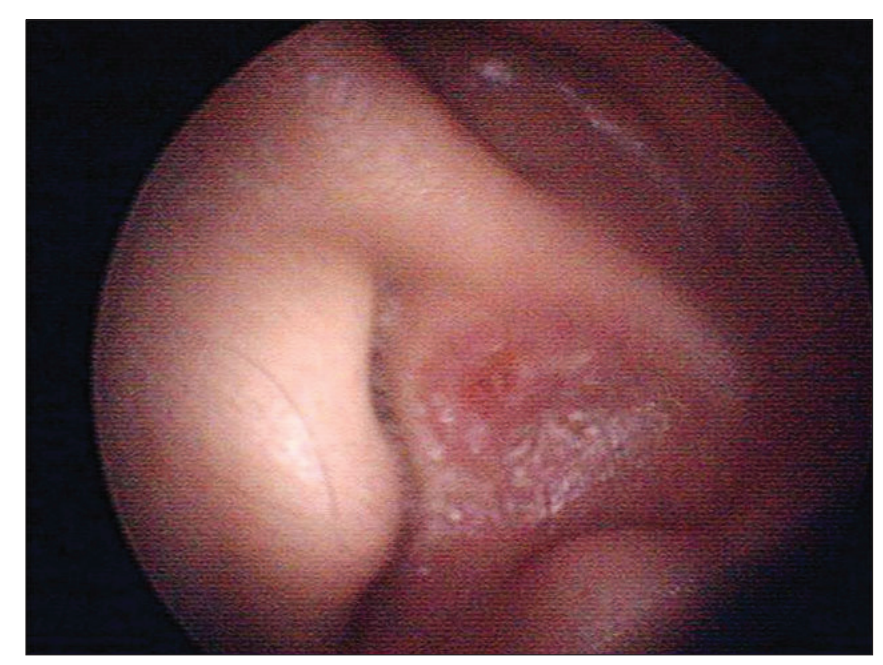

Fig. 1. Clinical photo of the left ear. Crust on the auricle. men, and there was no evidence of a brainstem lesion (Fig. 3A). A computed tomography scan of the neck revealed asymmetry of the jugular foramina, and there was no evidence of upper respiratory infection (Fig. 3B).

On the day of the electrodiagnostic study, atrophy of the left trapezius muscle was observed. The left scapula was displaced more laterally, compared to the right one, and an inferior angle of the left scapula was rotated internally. The winged scapula became more prominent with shoulder flexion, and manual muscle tests showed decreased muscular strength of Medical Research Council (MRC) grade 3 in left shoulder abduction and MRC grade 4 in left shoulder flexion. There was no limitation in the active or passive range of motion of the left shoulder, and there was no impairment of sensation in the neck and both upper extremities. Moreover, deep tendon reflexes of the upper extremities were normal.

During the motor nerve conduction study, amplitudes of compound muscle action potentials in the left spinal accessory nerve recorded from the left upper and mid trapezius muscles were absent. The amplitude of compound muscle action potential recorded from the lower trapezius muscles decreased to $0.4 \mathrm{mV}$ on the left side compared to $2.8 \mathrm{mV}$ on the right side. The distal latency of compound muscle action potential recorded from the lower trapezius muscles was delayed by $6.55 \mathrm{~ms}$ on the left side compared to $4.75 \mathrm{~ms}$ on the right side (Table 1 ).

Needle electromyography showed increased insertional activities in the left sternocleidomastoideus, abnormal spontaneous activities at rest and reduced interferential patterns on maximal volition in the left trapezius muscles. However, there were no abnormal spontaneous activities at rest in the muscles of the tongue, face, cervical spine, and left upper extremity. Based on these findings, the patient was diagnosed with Vernet syndrome, involv-
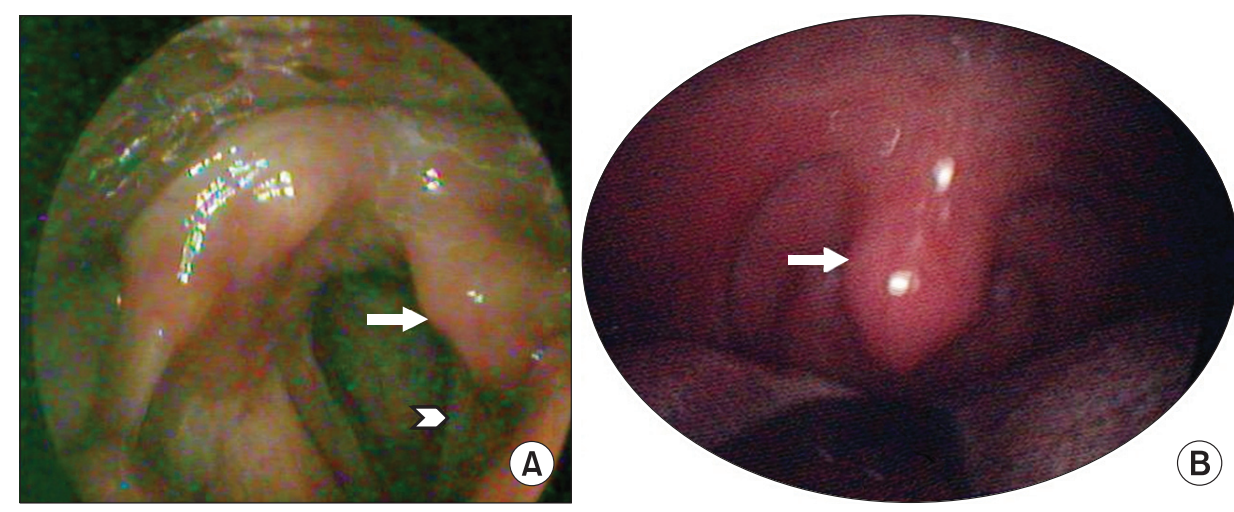

Fig. 2. Clinical photos of the left uvula and vocal cord in laryngoscopic view. (A) Asymmetric left vocal cord (arrow head) and ipsilateral arytenoid (arrow) movement, especially hypomobile abduction during respiration. (B) Mild deviation of the uvula to the right side (arrow). 

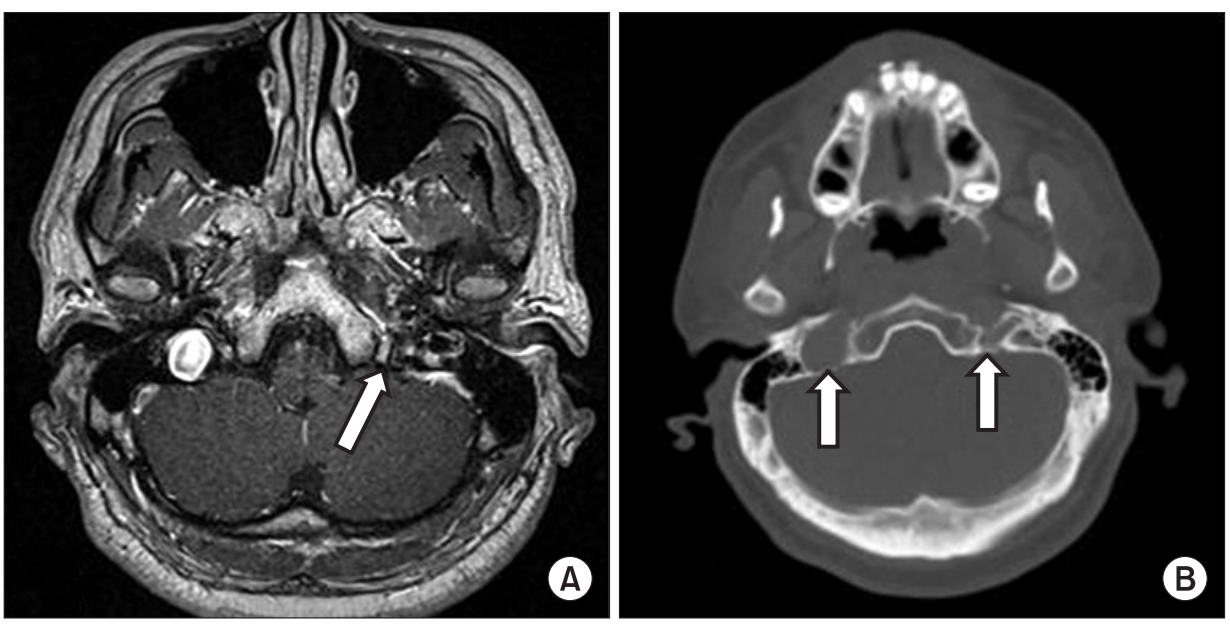

Fig. 3. (A) Magnetic resonance imaging of the temporal bone. Axial T1-weighted image at the medullary level shows no evidence of brainstem lesion. There is no nodular lesion in the left jugular foramen (arrow), which is smaller than the right. (B) Computed tomography scan reveals asymmetry of the jugular foramina (arrows).

Table 1. Results of motor nerve conduction study

\begin{tabular}{llcc}
\hline \multicolumn{1}{c}{ Nerve (recording site) } & Stimulation site & $\begin{array}{c}\text { Amplitude (mV) } \\
\text { (right/left) }\end{array}$ & $\begin{array}{c}\text { Latency (ms) } \\
\text { (right/left) }\end{array}$ \\
\hline Spinal accessory (upper trapezius) & Posterior SCM & $2.0 / \mathrm{NR}$ & $3.90 / \mathrm{NR}$ \\
Spinal accessory (mid trapezius) & Posterior SCM & $3.8 / \mathrm{NR}$ & $3.60 / \mathrm{NR}$ \\
Spinal accessory (lower trapezius) & Posterior SCM & $2.8 / 0.4$ & $4.75 / 6.55$ \\
Long thoracic (serratus anterior) & Erb's point & $0.3 / 0.4$ & $0.55 / 0.40$ \\
\hline
\end{tabular}

SCM, sternocleidomastoid; NR, no response.

ing the left ninth, tenth, and eleventh cranial nerves, attributable to varicella-zoster virus.

Acyclovir, an antiviral drug, was administered intravenously with a dose of $250 \mathrm{mg}$, three times a day, for five days. The patient was then orally given $250 \mathrm{mg}$ of famciclovir, three times a day, for the next four days. He also underwent physical therapy at an outpatient clinic. After three months, the left earache (otalgia) and shoulder pain subsided. According to the follow-up manual muscle test (MRC), the left upper extremity showed a marked improvement-left shoulder abduction grade 4 and left shoulder flexion grade 5 .

\section{DISCUSSION}

The present case involves Vernet syndrome caused by the varicella-zoster virus in which the damage of the glossopharyngeal and vagus nerves were confirmed by neurological examination and laryngoscopy and the damage of the spinal accessory nerve was confirmed by an electrodiagnostic study.

The pathogenic mechanism of concurrent involvement of multiple sensory ganglia by varicella-zoster virus has been elucidated by several hypotheses. First, numerous anatomical interconnections have been denoted between the lower cranial and upper cervical nerves, which is defined as a spinal accessory nerve plexus with high individual variation. The communication between the lower cranial and upper cervical nerves may explain the simultaneous involvement of cranial and cervical nerves by reactivation, thus spreading the varicella-zoster virus [5]. Second, other dissemination routes of varicella-zoster virus is thought to involve simultaneous reactivation of the varicella-zoster virus in multiple ganglia and inter-connecting nerves [6]. Third, varicella-zoster virus-induced cranial polyneuropathies can occur by the spreading of the virus through a common blood supply [7].

Jugular foramen syndrome generally refers to paralysis of one or more nerves of four specific cranial nerves. It also refers to neurological symptoms involving the glossopharyngeal nerve, vagus nerve, and spinal accessory nerve. By narrowing definition, jugular foramen syndrome is then known as Vernet syndrome [1]. The glossopharyngeal nerve, the vagus nerve and the spinal accessory nerve emerge from the posterolateral sulcus of the medulla oblongata, pass through the basal cistern and finally exit the cranium through the jugular foramen [1]. 
The causes of Vernet syndrome are primary tumors such as paraganglioma, meningioma, and schwannoma, metastatic tumors at the skull base, inflammation such as meningitis and malignant otitis externa, and sarcoidosis, Guillain-Barre syndrome, and trauma [4]. There are few case reports of varicella-zoster virus as a rare cause of Vernet syndrome $[8,9]$. The jugular foramen is divided into two parts?the pars nervosa located anterior and the pars venosa located posterior. In a report by Hayashi et al. [8] among case reports about Vernet syndrome by the varicella-zoster virus, there was ipsilateral hypoplasia of pars venosa detected using cranial helical computed tomography. Hayashi et al. [8] surmised that anatomical narrowing of the jugular foramen by ipsilateral hypoplasia may contribute to entrapment of the affected nerves at their passage through the foramen. In our case, there was no hypoplasia of the jugular foramen, and the jugular foramen in the left side was smaller than the right side. However, the right jugular foramen is usually larger than the left; in previous reports, the right foramen was the larger in 662 cases out of 1,022, while the left was the larger in 216 cases and they were the same size in only 114 cases [10]. Thus, it is unclear whether the left jugular foramen size contributed to Vernet syndrome in the present case, and further research is needed. The general prognosis of Vernet syndrome is unknown; however, treating Vernet syndrome with combined therapy with antiviral agents and steroids has shown a good prognosis showing restored muscle strength in shoulder joint abduction with improved dysphagia and hoarseness $[8,9]$.

The limitations of this case report are as follows. First, the MRI of the temporal bone in this patient was not high enough in resolution or thin enough in section imaging; thus, the edema or contrast enhancement in the affected left lower cranial nerves could not be confirmed through MRI. Second, an early electrodiagnostic study for vagus nerves regarding the vocal cord paralysis and a follow-up electrodiagnostic study for left spinal accessory neuropathy with axonopathy confirmed in the previous examination were not conducted.

In this case, a bullosa lesion was seen in the external auditory meatus, thus allowing assumption of varicellazoster virus infection in its early stage. However in a case report by Hayashi et al. [8], bullosa was not observed but varicella-zoster virus infection was confirmed through a blood test. Therefore, in cases of suspected jugular foramen syndrome or Vernet syndrome regardless of the presence of rash, varicella-zoster virus infection should be considered in addition to trauma, tumor or vascular lesions.

\section{CONFLICT OF INTEREST}

No potential conflict of interest relevant to this article was reported.

\section{REFERENCES}

1. Robbins KT, Fenton RS. Jugular foramen syndrome. J Otolaryngol 1980;9:505-16.

2. Hunt JR. The symptom-complex of the acute posterior poliomyelitis of the geniculate, auditory, glossopharyngeal and pneumogastric ganglia. Arch Intern Med 1910;5:631-75.

3. Park JH, Park IS, Ha JS, Sim JH, Sul SY. Dysphagia associated with jugular foramen syndrome due to traumatic brain injury. J Korean Acad Rehabil Med 2001;25:163-7.

4. Ha SW, Kim JK, Kang SJ, Kim MJ, Yoo BG, Kim KS, et al. A case of Vernet's syndrome caused by non-specific focal inflammation of the neck. Korean J Clin Neurophysiol 2007;9:81-4.

5. Brown H. Anatomy of the spinal accessory nerve plexus: relevance to head and neck cancer and atherosclerosis. Exp Biol Med (Maywood) 2002;227:5708.

6. Hashemilar M, Ghabili K, Shoja MM, Savadi-Oskouei D, Keyvani H. Varicella-zoster virus reactivation from multiple ganglia: a case report. J Med Case Rep 2009;3:9134.

7. Kleinschmidt-DeMasters BK, Gilden DH. Varicellazoster virus infections of the nervous system: clinical and pathologic correlates. Arch Pathol Lab Med 2001;125:770-80.

8. Hayashi T, Murayama S, Sakurai M, Kanazawa I. Jugular foramen syndrome caused by varicella zoster virus infection in a patient with ipsilateral hypoplasia of the jugular foramen. J Neurol Sci 2000;172:70-2.

9. Kawabe K, Sekine T, Murata K, Sato R, Aoyagi J, Kawase $\mathrm{Y}$, et al. A case of Vernet syndrome with varicella zoster virus infection. J Neurol Sci 2008;270:209-10.

10. Gejrot T. Jugular syndrome. Acta Otolaryngol 1964;57: 450-8. 